Alberto García-Lledó Javier Gómez-Pavón ${ }^{2}$ Juan González del Castillo ${ }^{3}$ Teresa Hernández-

Sampelayo ${ }^{4}$

Mari Cruz Martín-Delgado ${ }^{5}$ Francisco Javier Martín Sánchez ${ }^{6}$

Manuel Martínez-Sellés ${ }^{7}$ José María Molero Garcia ${ }^{8}$ Santiago Moreno Guillén ${ }^{9}$ Fernando RodríguezArtalejo $^{10}$ Julián Ruiz-Galiana" Rafael Cantón ${ }^{12}$ Pilar De Lucas Ramos ${ }^{13}$ Alejandra Garcia-Botella ${ }^{14}$ Emilio Bouza ${ }^{15}$

\section{Pharmacological treatment of COVID-19: an opinion paper}

\author{
${ }^{1}$ Cardiology Service. Prince of Asturias Hospital. University of Alcalá. Madrid. \\ ${ }^{2}$ Geriatrics Service. Central Hospital of the Red-Cross. Alfonso X el Sabio University. Madrid. \\ ${ }^{3}$ Emergency Service. San Carlos University Clinical Hospital. Complutense University. Madrid. \\ ${ }^{4}$ Pediatrics and ACES Service. Gregorio Marañón General University Hospital, Complutense University. Madrid. \\ ${ }^{5}$ Intensive Medicine Service. Torrejón University Hospital. Francisco de Vitoria University. Madrid. \\ ${ }^{6}$ Geriatrics Service. San Carlos University Clinical Hospital. Complutense University. Madrid. \\ ${ }^{7}$ Cardiology Service. Gregorio Marañón General University Hospital, European University. Madrid. \\ ${ }^{8}$ Family Medicine. Infectious diseases. Madrid. \\ ${ }^{9}$ Infectious Diseases Service. Ramón y Cajal Hospital. University of Alcalá de Henares. Madrid. \\ ${ }^{10}$ Department of Public Health. Autonomous University. Madrid. \\ ${ }^{11}$ Internal Medicine Service. Ruber International Hospital. Madrid. \\ ${ }^{12}$ Microbiology Service. Ramón y Cajal Hospital and Ramón y Cajal Institute for Health Research (IRYCIS). Spanish \\ Network for Research in Infectious Pathology (REIPI). Madrid. \\ ${ }^{13}$ Emeritus. Pneumology Service. Gregorio Marañón General University Hospital, Complutense University. Madrid \\ ${ }^{14}$ General Surgery Service. San Carlos University Clinical Hospital. Complutense University. Madrid. \\ ${ }^{15}$ Clinical Emeritus, Community of Madrid. Clinical Microbiology and Infectious Diseases Service of the Gregorio \\ Marañón General University Hospital, Complutense University. CIBERES. Cyber of Respiratory Diseases. Madrid
}

Article history

Received:27 November 2021; Accepted: 6 December 2021; Published: 11 December 2021

\section{ABSTRACT}

The precocity and efficacy of the vaccines developed so far against COVID-19 has been the most significant and saving advance against the pandemic. The development of vaccines has not prevented, during the whole period of the pandemic, the constant search for therapeutic medicines, both among existing drugs with different indications and in the development of new drugs. The Scientific Committee of the COVID-19 of the Illustrious College of Physicians of Madrid wanted to offer an early, simplified and critical approach to these new drugs, to new developments in immunotherapy and to what has been learned from the immune response modulators already known and which have proven effective against the virus, in order to help understand the current situation.

Keywords: COVID-19, SARS-CoV2, treatment, Remdesivir, Favipiravir, Molnupiravir, PF-07321332, Paxlovid, convalescent plasma, Sotrovimab, Banlanivimab, Etesevimab, Casirivimab, Imdevinab, AZD7442, Ciganilmab, Tixagevimab, Evusheld, BRII-196, BRII-198, Dexamethasone, Corticosteroids, Tocilizumab, Sarilumab, Anakinra, Canakinumab, Baricitinib, Tofacitinib, Ruxolitinib, Adalimumab, Certolizumab, Infliximab, Etanercept, Golimumab, Itolizumab, Ravulizumab, Lemilumab, Ivermectin, Colchicine, Vitamin D, Metformin, Fluvoxamine, Azithromycin, Hydroxychloroquine, Lopinavir/Ritonavir.

\section{Correspondence:}

Emilio Bouza

Servicio de Microbiologia Clinica y Enfermedades Infecciosas del Hospital General

Universitario Gregorio Marañón, Universidad Complutense. CIBERES. Ciber de Enfermedades

Respiratorias. Madrid

E-mail:emilio.bouza@gmail.com

All authors belong to the Scientific Committee on COVID-19 of the Madrid College of Physicians (ICOMEM).

Tratamiento farmacológico del COVID-19: un documento de opinión

\section{RESUMEN}

La precocidad y la eficacia de las vacunas desarrolladas hasta ahora frente al COVID-19, ha sido el avance más significativo y salvador frente a la pandemia. El desarrollo vacunal no ha impedido, durante todo el periodo de la pandemia, la búsqueda constante de remedios terapéuticos, tanto entre los medicamentos ya existentes y con indicaciones diversas, como en el desarrollo de nuevos fármacos. Sobre estos nuevos fármacos, sobre las novedades en la inmunoterapia y sobre lo aprendido de los moduladores de la respuesta inmune ya conocidos y que se han mostrado eficaces frente al virus, el Comité Científico del COVID-19 del Ilustre Colegio de Médicos de Madrid ha querido ofrecer una aproximación precoz, simplificada y critica que pueda ayudar a comprender la situación actual.

Palabras clave: COVID-19, SARS-CoV2, tratamiento, Remdesivir, Favipiravir, Molnupiravir, PF-07321332, Paxlovid, plasma de convalecientes, Sotrovimab, Banlanivimab, Etesevimab, Casirivimab, Imdevinab , AZD7442, Ciganilmab, Tixagevimab, Evusheld, BRII-196, BRII-198, Dexametasona, Corticosteroides, Tocilizumab, Sarilumab, Anakinra, Canakinumab, Baricitinib, Tofacitinib, Ruxolitinib, Adalimumab, Certolizumab, Infliximab, Etanercept, Golimumab, Itolizumab, Ravulizumab, Lemilumab, Ivermectina, Colchicina, Vitamina D, metformina, Fluvoxamina, Azitromicina, Hidroxicloroquina, Lopinavir/Ritonavir. 


\section{INTRODUCTION}

With the achievement of useful vaccines against COVID-19, whose efficacy is extraordinarily high but not absolute, and in view of the possibility that new variants of the virus may limit its efficacy, it is pertinent to turn our attention from the preventive to the therapeutic sphere. In addition, there is still a large number of unvaccinated persons. In the case of children aged 5 to 11 years, the European Medicines Agency (EMA) has approved the Comirnaty vaccine on 25 November 2021 [1].

The treatments against the disease are beginning to bear objective and significant fruit both in the field of direct antiviral therapy and in that of anti-inflammatory and immunotherapeutic treatment. A good example of this is the repositioning of monoclonal antibodies or the presentation of new effective antiviral agents that can be administered orally.

The Scientific Committee of COVID-19, of the Illustrious College of Physicians of Madrid (ICOMEM) has received and has been asked several questions about the present reality of the pharmacological treatment of COVID-19, to which the group has tried to give answers, after deliberation and consensus.

This document is not intended to be an exhaustive review of the state of the art of pharmacological treatment of the disease caused by SARS-CoV-2, but rather to offer a current, summarized and easily understandable perspective that includes the situation in Spain.

In the following pages we have compiled the scientific evidence that we have been able to collect, also providing the opinion of the ICOMEM working group.

\section{SOME CLINICALLY EFFECTIVE ANTIVIRALS AGAINST COVID-19}

In a disease of viral etiology, with some very aggressive and rapidly evolving forms, it is logical that drug treatments with antiviral activity began to be used early and, to a certain extent, indiscriminately, from the onset of the pandemic. We will confine ourselves here to listing those that have shown some efficacy in clinical trials or that seem very promising in this respect.

Remdesivir is a prodrug in monophosphate form that is metabolized to active adenosine triphosphate. It inhibits the replication of several families of RNA viruses, including coronaviruses. This drug had been studied against Ebola and Marburg viruses and clinical trials in SARS-CoV-2 infection started early [2-9]. Preclinical data showed that early treatment could decrease viral load, reduce lung damage and improve survival.

To date, although the drug has been approved for severe patients by the FDA and EMA, the results cannot be considered uniformly conclusive as some clinical trials have shown discordant results [5-11]. The first randomized, placebo-controlled, phase III clinical trial with remdesivir was published in 2020. It included 237 patients, with severe disease and $\mathrm{O}_{2}$ desaturation, who received treatment for 10 days. In this first trial, no clinical benefits were obtained, but a trend towards improvement was observed when treatment was started early. [12]. Negative results were also found within the Solidarity study in which 405 hospitals in 30 countries participated. A total of 11,330 patients were included in different groups, of whom 2,750 were assigned to remdesivir. No improvement in clinical outcome or mortality was observed in this study [13]. In the multi-center DisCoVeRy study, which included more than 800 patients [14] no clear benefit was demonstrated either. However, in the ACT-1 study, with more than 1,200 randomized patients, a more rapid clinical improvement was demonstrated in patients receiving remdesivir versus placebo and even a reduction in all-cause mortality. This trial led to FDA approval of the drug [15].

In a meta-analysis that included 5 randomized, placebo-controlled clinical trials with a total of 13,594 patients, those treated with remdesivir showed a more rapid clinical improvement and a reduction in the number of days of hospitalization. The differences in mortality were not significant, although there was a trend in that direction in the 5-day treatment studies [5].

In an observational study carried out in Spain at the Hospital Clínico de Barcelona, the use of remdesivir improved survival, with greater efficacy in patients who received treatment earlier, with a total reduction in the risk of death of 62\% [16]. Other studies showed similar results, such that treated patients had less need for mechanical ventilation and lower mortality $[17,18]$.

Remdesivir is therefore included as an effective drug in guidelines such as that of the Spanish Society of Infectious Diseases (SEIMC), indicated for patients in severe but not critical condition, with less than ten days of evolution. Similarly, the IDSA recommends remdesivir in hospitalized patients but not in critically ill patients $[19,20]$.

Recent studies have shown a decrease in the combined endpoint of COVID-related hospitalization and all-cause death of $87 \%$ in outpatients at high risk of progression treated for 3 days with remdesivir [21].

Favipiravir is a nucleoside, prodrug, antiviral, broad-spectrum, RNA-dependent, RNA polymerase-dependent antiviral drug that has already been used in the treatment of influenza and studied against SARS-CoV-2, preferably in Japan and other Asian countries [22].

It has been compared, in small studies, with drugs whose ineffectiveness has been proven a posteriori, without showing significant differences. Such is the case with hydroxychloroquine [23], lopinovir/ritonavir [24], inhaled B interferon [25] and with baloxavir [26] .

Finally, in a randomized, open-label, phase 3 study in cases of mild or moderate COVID, again with few cases (150 patients), a comparison was made with standard treatment, without the study allowing, in our opinion, any clear conclusion to be drawn [27]. 
For all these reasons, in our opinion, this drug does not yet have a study that establishes a clear efficacy and must still be considered among the experimental drugs $[28,29]$.

Molnupiravir, an orally administered drug, has recently been approved at least in the United Kingdom and the United States for use in patients with mild to moderate COVID-19. It is a prodrug with activity against RNA viruses. Preclinical animal studies have shown efficacy, with a broader spectrum than even remdesivir, and Phase I human clinical trials have shown good levels of safety [30]. A phase II clinical trial has proven its efficacy in terms of viral clearance at 7 days [31], including pharyngeal clearance of viruses.

Preliminary data from Phase III studies have revealed a significant reduction in the rate of disease progression, hospitalizations, need for ICU and death in the group of patients starting with mild or moderate disease. In contrast, no significant results are obtained in patients with advanced and severe disease [32].

Readers interested in more information on this new drug can find it in the following references [33-39].

PF-07321332 (Paxlovid ${ }^{\varpi}$, Pfizer), is a ritonavir-boosted protease inhibitor that would reduce the risk of hospitalization or death in $90 \%$ of subjects with mild to moderate disease.

PF -07321332 targets the major protease (Mpro) of SARSCOV-2 that processes the two polyproteins through at least 11 cleavage sites. The amino acid sequence and three-dimensional structure of Mpro are highly conserved across the Coronavirinae subfamily, providing a strong basis for the design of therapeutics to target potentially immune-evasive SARSCoV-2 variants $[40,41]$.

Pfizer has just announced at a press conference that its product Paxlovid $^{\circledast}$ (PF-07321332 + ritonavir) reduces the risk of hospitalization or death by $89 \%$, compared to placebo, in adults not hospitalized but at high risk of poor outcome at the conclusion of its EPIC study (Phase 2/3). The data will be submitted to the U.S. FDA for emergency use authorization (EUA) as soon as possible [42]. In patients treated within 3 days of symptom onset (primary endpoint); $0.8 \%$ of patients receiving Paxlovid ${ }^{\varpi}$ required hospitalization in the first 28 days (3/389 hospitalized, no deaths), compared to $7.0 \%$ of patients receiving placebo (27/385 hospitalized with 7 subsequent deaths). The primary analysis of the interim dataset evaluated 1,219 adults enrolled through September 29, 2021. At the time the decision was made to discontinue patient recruitment, enrollment was at $70 \%$ of the planned 3,000 patients. Treatment-emergent adverse events were comparable between Paxlovid ${ }^{\oplus}$ (19\%) and placebo (21\%), most of which were mild in intensity.

\section{CONVALESCENT PLASMA AND IV IMMUNOGLOBULINS}

Immunoglobulins and convalescent plasma (CP) is obtained from persons who have recovered from COVID-19.
Since the primary host immune response appears 10 to 14 days after infection, plasma should be collected from donors no earlier than the second or third week after SARS-CoV-2 infection [43].

Plasma would provide passive immunity based on antibodies and therefore could reduce both the severity and duration of the disease, so it could be indicated in hospitalized patients and with special interest in immunosuppressed patients with deficient antibody production. As a human blood product it can cause the same reactions as transfusions (allergic and anaphylactic reactions, hemolysis, fluid overload, etc.), but studies consistently show that plasma transfusion is safe with effects similar to those of ordinary transfusions [44-51].

However, despite the justification for its use, the experience in other viral epidemics and its safety, there are still no clear results in terms of efficacy. It began to be used in moderate-severe COVID-19 with publication of observational studies and clinical trials [46-48], with systematic review and meta-analysis $[45,46]$, which have provided inconclusive results. Furthermore, these trials were heterogeneous with respect to the characteristics of the convalescent plasma used (e.g. in terms of antibody content and stratification of recipient patients according to their serological status).

Given these findings, the FDA argued that a "totality of evidence" suggested that the benefits of convalescent plasma would outweigh its risks and, given the lack of effective treatments, granted an Emergency Use Authorization (EUA) and provided guidance on the manufacture and use of convalescent plasma in hospitalized patients with signs of progressive infection [44].

Outside the U.S., a randomized, open-label, controlled clinical trial in 27 hospitals in Spain is worth mentioning [49] in which no differences were obtained in terms of overall mortality $(11.7 \%$ in the treated group vs. $16.4 \%$ in the control group, $p=0.205)$, nor in terms of progression at 14 days. The PLACID study, carried out in India [50], also failed to demonstrate a decrease in disease progression and mortality. In summary, at the present time, convalescent plasma is not a treatment approved by the European Medicines Agency and even uncontrolled compassionate use of this procedure should be discouraged.

\section{MONOCLONAL ANTIBODIES USABLE IN MONOTHERAPY}

The world of monoclonal antibodies and the data on their activity have had a very important boost recently and we consider them to be an area of great interest. In this section we will discuss sotrovimab, which is indicated for monotherapy.

Sotrovimab. It is a recombinant engineered humanized monoclonal antibody $(\mathrm{lgG})$ that binds with high affinity to a highly conserved epitope in the receptor binding domain (RBD) of the S protein (spike) of SARSCoV-2. Its exact mechanism of action is not well understood, but it appears to prevent fusion 
after the virus binds to the human angiotensin 2-converting enzyme receptor $\left(\mathrm{ACE}_{2}\right)$.

Interim results from the COMET-IC (Early Treatment of COVID-19 in Outpatients) Phase II clinical trial were published in October 2021 [52]. This multicenter, double-blind trial evaluated the clinical course after administration of a single intravenous infusion of sotrovimab in 291 adult patients diagnosed with mild to moderate COVID-19 (Sat $02 \geq 94 \%$ on room air), not hospitalized, within the first 5 days of symptom progression versus a placebo group of 292 infected. Patients included in the trial were 18 years of age or older and were at high risk for progression of COVID- 19 because of their age ( $\geq 55$ years) or because they had at least one risk factor for progression to severe disease [52]. The primary efficacy outcome was hospitalization (for $>24$ hours) for any cause or death within 29 days after randomization. The use of sotrovimab was associated with an $85 \%$ reduction in the relative risk of progression to severe or critical illness and up to a 79\% reduction in the risk of all-cause hospitalization or death through day 29. In addition, no safety issues were identified that compromised treatment [52].

In May 2021, the FDA authorized the emergency use of sotrovimab in the US [53]. In Europe, it is part of the European Commission's portfolio of promising treatments against COVID-19 [54]. In May 2021, the Committee for Medicinal Products for Human Use (CHMP) issued its positive opinion on the drug, following review of data from the interim analysis of data from the Phase III Comet-ICE study [55] and will be studied by the European Medicines Agency (EMA) for possible authorization.

The COMET study demonstrated that intramuscular administration of sotrovimab is not inferior and offers similar efficacy to the intravenous formulation in a population at high risk of poor outcome. IM administration may facilitate its administration in primary care.

\section{MONOCLONAL ANTIBODIES USED IN COMBINATION}

Bamlanivimab + etesevimab. In November 2020, the IgG1 neutralizing monoclonal antibody bamlanivimab (LYCoV555; Lilly) received emergency use authorization (EUA) from the FDA for the treatment of newly diagnosed mild to moderate COVID-19 in patients 12 years of age and older, body weight equal or superior to $40 \mathrm{~kg}$, in good baseline condition but at high risk for progression to severe disease or requiring hospitalization [56].

Subsequently, in April 2021 the FDA revoked the US clearance of the monotherapy, due to the progressive increase of COVID-19 cases in the US caused by SARS-CoV-2 variants resistant to such monotherapy [57].

This revocation did not affect the combined use of bamlanivimab and etesevimab, which maintained its indication for emergency use. In a phase 3 clinical trial comparing single intravenous administration of the combination of bamlanivimab and etesevimab versus placebo within 3 days of laboratory confirmation of SARS-CoV-2 infection, the combination led to a lower incidence of COVID-19-related hospitalization and death from any cause on day 29 and accelerated the decline in SARS-CoV-2 viral load [58].

In the trial (BLAZE-1), the mean decrease in SARS-CoV-2 viral load at day 11 , the primary endpoint, was significantly greater with bamlanivimab plus etesevimab than with placebo. Hospitalization for COVID-19 or death from any cause at day 29 occurred significantly less frequently with the antibody combination than with placebo (2.1\% vs. $6.6 \%$; HR 0.32; NNT 22.5). No deaths occurred in the antibody group, compared with 10 in the placebo group [59].

In a second trial (BLAZE-4), the FDA selected $700 \mathrm{mg} / 1400$ $\mathrm{mg}$ as the licensed dose for use of bamlanivimab and etesevimab together, prompting the manufacturer to study this dose in a new cohort (BLAZE-1.5). The rate of hospitalization for COVID-19 or death from any cause at day 29 was significantly lower with the antibodies than with placebo (0.8\% vs. 5.4\%; HR 0.13; NNT 21.5).

Bamlanivimab and etesevimab should be administered as soon as possible after a positive SARS-CoV-2 test result and within 10 days of the onset of COVID-19 symptoms. Patients should be treated in a facility staffed and equipped for the management of anaphylaxis and should be monitored for hypersensitivity reactions during drug administration and for at least 1 hour after completion of the infusion.

In March 2021, the Committee for Human Medicinal Products (CHMP) of the European Medicines Agency (EMA), began the ongoing review procedure of the results of studies with bamlanivimab and etesevimab, for the treatment of confirmed COVID-19. The review ended without issuing the conclusions, once the company Eli Lilly Netherlands BV, the marketer of the two molecules, informed the Agency on October 29, 2021 that it was withdrawing from the process [60]. In its letter notifying the Agency of the withdrawal, the company stated that it was withdrawing because EMA required prospective concurrent validation data that could only be generated through the production of new batches of active substance and that it was not in a position to generate such additional data.

This product has been withdrawn from the evaluation process in Europe.

Casirivimab + imdevimab. Regeneron's monoclonal antibodies casirivimab (REGN10933) and imdevimab (REGN10987) are cleared for use together.

The FDA has cleared this combination of monoclonal antibodies to SARS-COV-2 on an emergency basis (REGEN-COV) for co-administration by intravenous or subcutaneous injection for the treatment of mild to moderate COVID-19 in individuals over 12 years of age and weighing no less than 40 $\mathrm{kg}$ who are at high risk for progression to severe COVID-19 $[61,62]$. Traditional risk groups would also include overweight patients or pregnant women, as well as those suffering from cardiovascular disease, hypertension or chronic respiratory disease (Table 1) $[61,63,64]$. 
In contrast, this combination could worsen the results if administered to patients hospitalized for COVID-19 or requiring high-flow oxygen or mechanical ventilation.

The mechanism of action is based on the fact that casirivimab and imdevimab bind to different sites of the receptor-binding domain of the SARS-CoV-2 spike protein, blocking its binding to the human ACE2 receptor.

FDA clearance was based on interim Phase 1/2 results from a double-blind trial (COV-2067) in which 799 outpatients with mild to moderate COVID-19 were randomized in a blinded fashion to receive a single intravenous infusion of monoclonals or placebo. Outcomes were assessed 28 days after infusion [64] and viral load at day 7 was significantly lower with the monoclonal combination than with placebo. There was also less need for hospitalization, emergency department visit or teleconsultation within 28 days after infusion (2.8\% vs. 6.5\%). Among patients at higher risk of disease progression, rates of poor outcome were 3\% with casirivimab and imdevimab and $9 \%$ with placebo. The combination is protective against variants of concern known to date [65].

Subsequent data in Phase 3 studies (COV-2067), in which 3,867 patients with mild or moderate COVID and at least one risk factor for progression to severe disease were randomized prompted the FDA to change the licensed dose of casirivimab and imdevimab from $1200 \mathrm{mg}$ to $600 \mathrm{mg}$ of each antibody $[64,66]$.

We are not aware of studies comparing this combination with other monoclonal antibody combinations. Anaphylaxis reactions have occasionally been detected with this combination, although they are very rare [64].

If intravenous infusion is not feasible and would result in a delay in treatment, casirivimab and imdevimab can be administered subcutaneously. The licensed dose is $600 \mathrm{mg}$ of casirivimab and $600 \mathrm{mg}$ of imdevimab administered in four consecutive 2.5- $\mathrm{ml}$ injections (2 injections of each antibody packaged separately, or 4 injections of the co-formulated formulation) at different sites on the thigh, back of the arm, or abdomen (except $5 \mathrm{~cm}$ around the umbilicus). If a prepared syringe cannot be used immediately after dilution, it can be refrigerated or left at room temperature for up to 4 hours. If refrigerated, the syringe should remain at room temperature for 20 minutes before administration.

Casirivimab and imdevimab should be administered in a facility staffed and equipped to manage anaphylaxis. Patients should be monitored for hypersensitivity reactions for at least 1 hour after antibody administration.

The combination of casirivimab and imdevimab has been administered with good tolerance to pregnant women [67].

In May 2021, the FDA has extended clearance for the use of the combination of casirivimab and imdevimab to post-exposure prophylaxis in high-risk individuals if they are not fully vaccinated or if they have a poor immune response to the vaccine $[68,69]$.

This indication expansion is based on the results of a rand- omized, double-blind, placebo-controlled trial in 1,505 healthy, unvaccinated patients aged $\geq 12$ years with no evidence of prior immunity who were household contacts of persons with SARS-CoV-2 infection (positive test within the previous 96 hours). Patients received a single subcutaneous dose of casirivimab and imdevimab (600 mg each) or placebo. Symptomatic SARS-CoV-2 infection within 4 weeks of randomization was significantly lower in patients who received the antibodies than in those who received placebo (1.5\% vs. $7.8 \%$ ). Among patients who developed symptomatic infection, the duration of symptoms was significantly shorter in the antibody group (mean 1.2 vs. 3.2 weeks with placebo). There were no hospitalizations or emergency department visits due to COVID-19 in the antibody group compared to 4 in the placebo group [70].

AZD7442: Cilgavimab (AZD1061) + Tixagevimab (AZD8895) (Evusheld). AZD7442 is a combination of two monoclonal antibodies from Astra Zeneca, AZD8895 (tixagevimab), a long-acting agent, and AZD1061 (cilgavimab), which simultaneously bind to distinct non-overlapping epitopes in the protein $S$ receptor binding domain to neutralize SARS-CoV-2. Both form a complex with the receptor binding domain (RBD) and have strong neutralizing activity against SARS-CoV-2 and variants with antigenic substitutions at the RBD [71].

They are currently being evaluated for single-dose administration (intramuscular or intravenous) to treat or prevent COVID-19. Preliminary results in treatment suggest a decrease in severity in patients. Applied to both pre-exposure and post-exposure prevention, the results of the studies are scheduled for completion in June 2022 [72].

Preliminary results of the preventive treatment have been reported by Astra Zeneca, announcing that AZD-7442 failed to improve outcomes in SARS-CoV-2 post-exposure prophylaxis. On the contrary, in pre-exposure prophylaxis, the study suggests its efficacy in reducing the risk of developing symptomatic COVID-19 by 77\%. Protection could be maintained for up to 12 months.

Combination of neutralizing monoclonal antibodies BRII-196 and BRII-198. BRII-196 and BRII-198 are noncompetitive anti-SARS-CoV-2 monoclonal antibodies. They reduce virus binding to the receptor and their structure allows for a long half-life of activity, according to data from a study (ACTIV-2), sponsored by NIAID and led by the ACTG.

A study evaluates the safety/efficacy of investigational agents for the treatment of non-hospitalized adults with mild-moderate COVID-19 under a randomized, blinded, controlled, adaptive platform. BRII-196/BRII-198 (1,000 mg each) is administered as single doses in sequential infusions to patients at high risk for clinical progression (i.e., age $\geq 60$ years or presence of other medical conditions) within 10 days of symptom onset and after positive test for SARS-CoV-2. The primary endpoint was hospitalization and/or death through day 28.

Between January and July 2021, 837 participants (418 active, 419 placebo) in various nations were randomized and 
received study product at the time when emerging variants were circulating. In the interim analysis, the BRII-196/BRII-198 combination had fewer hospitalizations (12 vs. 45 ) and deaths (1 vs. 9 AZD7442) compared to placebo. Grade 3 or higher adverse events (AEs) were observed less frequently among participants on BRII-196/BRII-198 than on placebo (3.8\% vs. 13.4\%), with no serious infusion or other reactions.

Thus, the BRII-196/BRII-198 combination appears safe, well tolerated, and demonstrated a significant reduction compared to placebo in the risk of hospitalization and/or death among adults with mild-moderate COVID-19 at high risk of progression to severe disease [73].

\section{THE ROLE OF CORTICOSTEROIDS IN THE TREATMENT OF SEVERE COVID-19}

The use of dexamethasone is recommended in critically ill patients with COVID 19 who require oxygen therapy or ventilatory support. The recommended dose is $6 \mathrm{mg}$ daily for 10 days or until hospital discharge. Comparison of dexamethasone $12 \mathrm{mg}$ daily versus $6 \mathrm{mg}$ has shown no difference in the results regarding efficacy (survival without life support at 28 days) and safety in the most critically ill patients [74]. If dexamethasone is not available, other glucocorticoids at equivalent doses (total daily doses of hydrocortisone $160 \mathrm{mg}$, methylprednisolone $32 \mathrm{mg}$ or prednisone $40 \mathrm{mg}$ ) may be considered, although the data supporting the use of these alternatives are more limited than those for dexamethasone [75-77]. In contrast, the use of dexamethasone (or other glucocorticoids) is not recommended for the prevention or treatment of mild to moderate COVID-19 (patients not receiving oxygen).

The World Health Organization (WHO) [77] has established two recommendations regarding the use of corticosteroids in COVID-19 patients:

1. Administration of systemic corticosteroids in preference to no administration for the treatment of severe and critically ill patients (strong recommendation, based on moderate certainty evidence).

2. Refraining from the use of corticosteroids in the treatment of non-critically ill COVID-19 patients (conditional recommendation, based on low certainty evidence).

This guideline is based on a reduction in 28-day mortality of $8.7 \%$ and $6.7 \%$ in critically or severely ill COVID-19 patients. In addition, systemic corticosteroids probably reduce the need for invasive mechanical ventilation [77]. The oxygen saturation threshold of 90\% for the definition of severe COVID 19 is considered arbitrary and is recommended to be adjusted to the patient's baseline situation.

The main study supporting these recommendations is Recovery [78] which shows a reduction in 28-day mortality in patients with COVID 19 with mechanical ventilation (29.3\% vs. $41.4 \%)$ or oxygen therapy (23.3\% vs. $26.2 \%)$ but not in patients without respiratory support (17.8\% vs. $14.0 \%)$. The main adverse events related to the use of corticosteroids have been related to hyperglycemia and hypernatremia [79] , as well as with new episodes of septic shock, invasive fungal infections, Strongyloides stercoralis hyperinfection in endemic areas, and gastrointestinal bleeding. As of April 2021, 42 clinical trials of corticosteroids in severe COVID-19 patients were ongoing and 16 had been completed but not published, possibly increasing the evidence available in the immediate future [79].

The use of corticosteroids in persistent COVID-19 interstitial lung disease has shown benefits in some observational series but clinical trials are needed to confirm these results [80].

\section{OTHER IMMUNOMODULATORY DRUGS}

Cytokine production in response to viral replication plays an important role in lung damage, in the need for mechanical ventilation and, globally, in the survival of patients with COVID-19. This has prompted research into the efficacy of immunomodulatory drugs that limit cytokine-associated effects. The demonstration of the beneficial effects of corticosteroids in patients with severe pneumonia reinforces anti-inflammatory/immunomodulatory therapy as a way to address severe disease.

The immunomodulatory drugs investigated are grouped into several families according to their mechanism of action (Table 1). Of these, only a few have sufficient data to be able to make a judgment on their use in COVID-19.

\begin{tabular}{l|c}
\hline Table 1 & $\begin{array}{l}\text { Immunomodulatory drugs investigated } \\
\text { in the treatment of COVID-19. }\end{array}$ \\
\hline Class (Mechanisms of action) & Drugs \\
\hline IL-6 inhibitors & Tocilizumab \\
& Sarilumab \\
IL-1 antagonists & Anakinra \\
& Canakinumab* \\
Bruton's Tirosin Kinase (BTK) inhibitors & Acalabrutinib* \\
Janus Kinase (JAK) inhibitors & Baricitinib \\
& Tofacitinib \\
& Ruxolitinib* \\
TNF inhibitors & Adalimumab* \\
& Certolizumab* \\
& Infliximab* \\
& Etanercept* \\
Anti CD ${ }_{6}^{*}$ monoclonal antibodies & Golimumab* \\
C5 complement inhibitors & Itolizumab* \\
GM-CSF inhibitors & Ravulizumab* $^{*}$ \\
\hline
\end{tabular}

* There is not enough data to consider its use. 
The drugs whose clinical trials and observational studies have shown results that make their use worth considering are grouped into three families: IL-6 inhibitors, IL-1 antagonists and JAK inhibitors.

The most widely evaluated IL-6 inhibitor is tocilizumab. Initial results from observational studies were very encouraging, but were not always followed by similar results in clinical trials. The registry clinical trials (COVACTA, EMPACTA) failed to show benefit in patients with severe pneumonia, including patients requiring ICU admission or mechanical ventilation [8185]. Some subsequent clinical trials showed that tocilizumab administration in patients with severe pneumonia is associated with a significant decrease in mortality and organ support-free time. [86-88]. Significantly, the RECOVERY study showed that tocilizumab was effective in reducing mortality in patients with inflammation data (CRP $>75 \mathrm{mg} / \mathrm{L}$ in this study) [89], similar to some observational studies $[90,91]$. Of particular importance was that the benefits of tocilizumab were felt even when the patient was receiving steroids. The positive results of these clinical trials have led most COVID-19 treatment guidelines to include it as an option in patients with severe pneumonia, especially if they have elevated markers of inflammation. Sarilumab is another IL-6 inhibitor that has been evaluated in clinical trials. The number of patients treated does not allow conclusions to be drawn and, at this time, it is recommended for use only in patients who for whatever reason cannot receive tocilizumab.

Among the JAK inhibitors, baricitinib and tofacitinib have obtained positive results in clinical trials. Both drugs have shown a decrease in progression to mechanical ventilation and mortality, independent of concomitant steroid use [92-95].

Finally, an IL-1 inhibitor, anakinra, has also shown beneficial effects on clinical progression and mortality in patients with severe pneumonia [96-98]. In a double-blind clinical trial, the drug demonstrated benefit especially in patients who had elevated suPAR levels (>6 ng/mL), a marker of severity in patients with COVID-19 [99].

There is no doubt that the group of drugs we are discussing have a role in the treatment of patients with severe COVID-19 pneumonia. It should be noted that, in a recent review, baricitinib and tofacitinib were included, along with dexamethasone and tocilizumab, as the drugs that had demonstrated a decrease in COVID-19-associated mortality in randomized clinical trials [95].

It is possible that anakinra could be added to this list. The timing of administration also seems to be well established. It should not be administered during the early stages of the disease, when antiviral drugs are preferentially indicated, and should be reserved for patients requiring oxygen therapy. Both dexamethasone and tocilizumab could also be administered in patients requiring mechanical ventilation or ECMO. Both JAK inhibitors and IL-6 inhibitors can and should be administered in conjunction with dexamethasone in patients in whom they are indicated.

Some doubts remain to be resolved. No comparative studies have been carried out between the different options and the profile of patients who can benefit optimally from each of them remains to be determined. The elevation of some plasma markers may help to make the decision. Elevated IL-6 and CRP have been shown to be suitable markers to identify patients who benefit from tocilizumab, suPAR has been shown to identify patients who benefit from anakinra. It is also not known whether the association of more than one of these immunomodulatory drugs adds any advantage to the isolated administration of each of them. The target on which they act is different, which could determine synergism with potentiation of the benefits.

\section{KNOWN DRUGS WITH OTHER INDICATIONS UNDER EVALUATION FOR COVID-19}

Ivermectin. Ivermectin is a broad-spectrum antiparasitic agent that has been shown to be effective against SARSCoV-2 in vitro [100]. Ivermectin is approved in some countries for the treatment of parasitic infections, but not for COVID-19. In particular, the World Health Organization does not recommend the use of this drug except in the context of a clinical trial [101] and other studies advise against its use [102-104].

Colchicine. Colchicine is a potent agent that inhibits multiple proinflammatory pathways, so it was thought that it could be useful in the control of the inflammatory complications of COVID-19. Colchicine is approved in some countries, such as Spain, for the treatment of gout and familial Mediterranean fever, but not for COVID-19, as it is considered that there is insufficient evidence of its usefulness, and it also has significant adverse effects, especially gastrointestinal. $[105,106]$. Therefore, it can only be used for the treatment of COVID-19 within a clinical trial.

Vitamin D. Vitamin D supplementation has been associated with lower risk of acute respiratory infections, such as influenza [100]. However, there are insufficient data to recommend or reject the use of vitamin $D$ for the prevention or treatment of COVID-19 [107]. A Cochrane review found a large heterogeneity of studies on this vitamin in the treatment of COVID-19, due to the different supplementation strategies, formulations, vitamin D level of the participants and the results found [108]. It is noteworthy that one of the first clues to the potential usefulness of vitamin D in COVID-19 was a pilot randomized controlled trial conducted in Spain, which observed that highdose calcifediol reduces the need for intensive care unit treatment in patients hospitalized for COVID-19 [109].

Metformin. Metformin is a first-line treatment for type 2 diabetes, but it has also shown some efficacy in infectious diseases, such as influenza and hepatitis C. In a July 2021 review, 4 observational studies were identified that showed a reduction in mortality among people using metformin on an outpatient basis [110]. However, the evidence is insufficient to recommend the use of this drug to reduce COVID-19-associated mortality [111]. 
Fluvoxamine. Fluvoxamine is an antidepressant drug (selective serotonin reuptake inhibitor and -1 receptor agonist) that also has certain anti-inflammatory and possibly antiviral effects. On October 27, 2021, the results of the TOGETHER trial, which is the largest randomized trial to date (741 patients on fluvoxamine and 756 on placebo) to evaluate the effectiveness of this drug in symptomatic patients with COVID-19 at high risk of developing severe COVID-19 in Brazil, were published on October 27, 2021 [112]. Compared to those treated with placebo, patients with fluvoxamine (100 mg twice a day for 10 days) reduced by $38 \%$ the frequency of hospitalization, defined as a stay of more than 6 hours in a COVID-19 emergency device or transfer to a tertiary hospital due to COVID-19. These results are very encouraging because of the high efficacy of the treatment, and because it is oral and very low cost, but they need to be replicated in new studies.

\section{DRUGS DISCARDED AFTER PROVING INEFFECTIVENESS}

Among the drugs that have been massively used and have now been shown to be ineffective, we would like to highlight hydroxychloroquine/chloroquine, azithromycin, and lopinavir/ ritonavir. We will now detail what motivated their use and why they are no longer in use.

Hydroxychloroquine and chloroquine are drugs approved for the treatment of lupus erythematosus, rheumatoid arthritis and malaria. They were among the first treatments used at the beginning of the pandemic. Hydroxychloroquine was thought to be more effective due to the results of in vitro experiments and pharmacokinetic models. However, published studies do not indicate that they have antiviral efficacy, nor do they improve clinical course or mortality. Neither the Solidarity clinical trial (CT) [113], nor Recovery [114], have shown benefit. The pooled relative risk of mortality from these trials was $1.11,95 \% \mathrm{Cl} 0.99-1.24$, with no apparent benefit in both ventilated and nonventilated patients. This $\mathrm{Cl}$ excludes any benefit of hydroxychloroquine in hospitalized patients. These trials also do not demonstrate excess mortality in relation to the use of hydroxychloroquine in hospitalized patients $[113,114]$.

Azithromycin has, in addition to its bacteriostatic activity, an immunomodulatory, anti-inflammatory, and antiviral effect $[115,116]$. It can also improve patients with respiratory distress syndrome $[117,118]$. Based on these facts, it has been used empirically in patients with COVID, especially in moderate-severe cases. Its use has also been justified with the intention of reducing bacterial superinfection in critically ill patients. A systematic review and meta-analysis of all types of clinical studies (including 17 papers) found no clinical improvement in patients with COVID-19 [119]. No statistically significant differences were found in the rate of mortality, mechanical ventilation or hospital admission between the control group and the group treated with azithromycin. In terms of safety, the use of this macrolide has a relatively safe profile. The risk of QT prolongation was also not statistically significant compared to previous studies [119].

Lopinavir/ritonavir is used for the treatment of human immunodeficiency virus (HIV-1). It was thought to be a potential treatment for SARS-COV-2, and was shown in vitro to achieve inhibition of several respiratory viruses, including SARS-CoV-1, and Middle East Respiratory Syndrome (MERS) $[120,121]$. However, the scientific evidence does not support its clinical use in COVID-19. A systematic review and meta-analysis evaluating the effects of lopinavir/ritonavir alone or in combination with other therapies do not report positive clinical effects [120]. Nor have larger clinical trials (RECOVERY and SOLIDARITY) demonstrated a reduction in mortality, initiation of invasive mechanical ventilation, or duration of hospitalization with this therapy. Adverse events were reported more frequently for lopinavir/ritonavir $(n=84)$ compared to both other antivirals and placebo [120].

In conclusion, hydroxychloroquine/chloroquine, azithromycin, and lopinavir/ritonavir although they have been widely used, are currently discarded for the treatment of COVID, since after large studies with large populations they have not shown benefit.

\section{PECULIARITIES OF THE USE OF ANTI-COVID DRUGS IN PREGNANT WOMEN AND CHILDREN}

In the current COVID-19 pandemic scenario, both women of childbearing age and pregnant women are a very large population at risk for SARS-COV-2 infection [122]. The situation of physiological immunotolerance of pregnancy seems to increase the risk of infection and serious complications [123], and there are more obstetric complications and higher rates of prematurity $[124,125]$.

The multiple safety barriers to include pregnant women in clinical trials, and the physiological changes of pregnancy, make it difficult to study new drugs in this population group [126-128].

We could summarize the drugs used for COVID in pregnant women in 3 groups [127] :

1.- Drugs that have not demonstrated efficacy against COVID-19, as listed in another section of this document, including hydroxychloroquine, chloroquine, lopinavir/ritonavir, Colchicine and Azithromycin.

2.- Drugs prohibited in pregnancy due to toxicity and teratogenic effect already known: thalidomide, and hypotensive drugs that act at the level of the renin angiotensin system and affect fetal renal development.

3.- New drugs, immunomodulators, with little knowledge in pregnant women. Among them are: tocilizumab. There is little experience with the use of tocilizumab in pregnant women with rheumatic disease and experts only recommend it if the benefit outweighs the potential risks [126].

Beta Interferon, a cytokine of the interferon family with 
antiviral antiproliferative and immunomodulatory activity, used in the treatment of maternal multiple sclerosis, has been proposed for the treatment of severe cases of COVID-19 but there are no recommendations for use in COVID-19 infected pregnant women. Remdesivir has insufficient experience in pregnant women. Finally, other drugs not specifically anti-COVID-19 used in the management of pregnant women such as fluorinated glucocorticoids (betamethasone or dexamethasone), used for fetal lung maturation if indicated, and methyl prednisolone and dexamethasone have been evaluated in prospective studies and have demonstrated efficacy in the treatment of severe maternal SARS-COV2 infection [125].

It is essential to remember the need to include pregnant women in clinical trials in order to have data that allow the use of already available and future drugs with safety and certainty of effectiveness, without having to do it in compassionate use or by extrapolation of data obtained in other population groups, or used with other indications [126].

SARS-COV-2 infection in children accounts for $10 \%$ of reported cases of COVID-19. [129, 130]. Although the majority of infected children do not require specific treatment for the virus, it should be remembered that between 4 and 8\% may require admission to the ICU [131-138].

Regarding treatment of COVID-19 in children, there are no data from large randomized, placebo-controlled clinical trials, and there are few observational studies to provide sufficient information to dictate treatment recommendations for COVID-19 in the pediatric population. The NIH Clinical Guidelines for treatment of COVID-19 contain specific recommendations and considerations for pediatric populations as dictated by an Expert Panel on the subject [139].

In summary:

Remdesivir is FDA cleared for the treatment of COVID-19 in children over 12 years of age, weighing more than $40 \mathrm{~kg}$. Also available on an emergency basis FDA (USA) for treatment of COVID-19 in hospitalized young children weighing between $3.5 \mathrm{~kg}$ and $40 \mathrm{~kg}$, or under 12 years of age weighing more than $3.5 \mathrm{~kg}$. [140].

Dexamethasone is recommended by an Expert Panel in hospitalized children with COVID-19 who require high-flow oxygen therapy, noninvasive ventilation, mechanical ventilation, or extracorporeal oxygenation (ECMO) (BIII). In contrast, it is not recommended in children who require little supplemental oxygen (nasal goggles).

3.- With monoclonal antibodies there is insufficient evidence for the recommendation or rejection of the use of this medication in children [141].

4.- COVID-19 convalescent plasma: Not recommended in hospitalized children on COVID-19, who do not require mechanical ventilation, unless administered in the course of a clinical trial (AIII). It is also not recommended for use in hospitalized children hospitalized with COVID-19 on mechanical ventilation (AIII). There are insufficient data on efficacy and safety. It could only be considered on an individual basis, in cases consulted with pediatric infectious disease specialists, using gamma globulin with high doses of immunoglobulin and patients who meet the criteria for its use.

5.- The evidence is insufficient to recommend or reject the use of tocilizumab in children.

6.- An expert panel speaks out against the use of sarilum$\mathrm{ab}$ in hospitalized children with CONVID-19 or PIMS outside the context of a clinical trial.

7.- Post-COVID pediatric hyperinflammatory syndrome (PIMS) is a rare but serious complication in older children and adolescents. It should be treated by a multidisciplinary team, which assesses the need or not for immunomodulatory treatment [142].

\section{CURRENT REGULATORY SITUATION OF DRUGS FOR PATIENTS WITH COVID-19 IN SPAIN}

Remdesivir is currently the only specific drug against COVID-19 approved by the AEMPS. It is indicated for treatment in adults and adolescents with pneumonia requiring supplemental oxygen [143].

Secondly, dexamethasone is another drug widely used in the treatment of COVID-19 and fully available in Spain [144].

The use of immunomodulators has become widespread, especially in patients at higher risk of poor outcome and in the inflammatory phase of the disease. The drugs used are approved for marketing in Spain, but in entities other than COVID-19. The most widely used are tocilizumab, authorized for the treatment of rheumatoid arthritis and cytokine release syndrome associated with treatment with CART (immunocellular therapy); Anakinra, authorized in rheumatoid arthritis, cryopyrin-associated syndromes, familial Mediterranean fever and Still's disease; and baricitinib, authorized in rheumatoid arthritis, moderate to severe, and atopic dermatitis. Regarding monoclonal antibodies, sotrovimab and the combination of casirivimab and imdevimab can be prescribed in our country for off-label indications. The European Medicines Agency (EMA) concluded that these monoclonal antibodies can be used to treat confirmed COVID-19 in adults and adolescents (aged 12 years or older and weighing at least $40 \mathrm{~kg}$ ) who do not require supplemental oxygen therapy and who are at risk of progressing to severe COVID-19 $[145,146]$.

The European Commission has granted marketing authorization for Ronapreve ${ }^{\circledR}$ (casirivimab and imdevimab) for the treatment of COVID-19 in adults and adolescents (aged 12 years and older and weighing at least $40 \mathrm{~kg}$ ) who do not require supplemental oxygen and who are at increased risk of worsening their disease, as well as for the prevention of COVID-19 in people aged 12 years and older and weighing at least $40 \mathrm{~kg}$ (pre- or post-exposure prophylaxis). This decision comes one day after the positive opinion of the Committee for Medicinal Products for Human Use (CHMP) of the European Medicines Agency (EMA), demonstrating the priority of the EMA and the European Commission to reduce review times for safe, effective 
and high quality therapies in the context of the public health emergency that is COVID-19 $[145,146]$.

Finally, the EMA's Committee for Human Medicinal Products (CHMP) has recently begun a review of the oral antiviral drug molnupiravir (also known as MK 4482 or Lagevrio). By reviewing data as they become available, the CHMP may issue an opinion on the drug's premarketing authorization.

\section{CONCLUSIONS}

1.- Remdesivir, molnupiravir and PF-07321332 (Paxlovid) are three antivirals with different mechanisms of action that have demonstrated efficacy in clinical trials in different markers of disease progression.

2.- At present, and after many published data, convalescent plasma cannot be considered a therapy of established efficacy in patients with COVID in any of their clinical situations.

3.- There are monoclonal antibodies, both marketed and in the process of being marketed, which, when administered early in the natural course of the disease, decrease progression to severe forms.

4.- Some monoclonal antibodies under investigation could, if their efficacy is demonstrated, be administered preventively and with long-term action.

5.- The role of dexamethasone in severe patients with COVID-19 is well established. The alternative position of other corticosteroids in equivalent doses is less clear. There is no indication for administration of dexamethasone in less severe situations.

6.- There are other immunomodulatory drugs with different targets of action that already have indications in patients with severe pneumonia and respiratory failure.

7.- Of the drugs already known with other indications, fluvoxamine seems especially promising in the treatment of COVID-19.

8.- Hydroxychloroquine, azithromycin, and the anti-HIV combination of lopinavir and ritonavir have been shown to be ineffective in different studies and have no place in the current treatment of COVID-19.

9.- Studies on efficacy, safety and tolerance in pregnant women and children of any of the above drugs are limited.

10.- At the time of writing, only remdesivir is approved in Spain by the AEMPS, in the antiviral group. Some monoclonal antibodies are available on a compassionate use basis and immune response modifiers are available off-label.

\section{FUNDING}

None to declare

\section{CONFLICTS OF INTEREST}

The authors declare no conflicts of interest

\section{REFERENCES}

1. European Medicines Agency. Comirnaty COVID-19 vaccine: EMA recommends approval for children aged 5 to 11. Accessed 26 november 2021 https://wwwemaeuropaeu/en/news/comirnaty-covid-19-vaccine-ema-recommends-approval-children-aged-5-11.

2. Lin HXJ, Cho S, Meyyur Aravamudan V, Sanda HY, Palraj R, Molton JS, et al. Remdesivir in Coronavirus Disease 2019 (COVID-19) treatment: a review of evidence. Infection. 2021;49(3):401-10. doi: 10.1016/j.bbrc.2020.11.043 7836944.

3. Santoro MG, Carafoli E. Remdesivir: From Ebola to COVID-19. Biochem Biophys Res Commun. 2021;538:145-50. doi: 10.2147/dddt. S261154 7425093.

4. Porter DP, Weidner JM, Gomba L, Bannister R, Blair C, Jordan R, et al. Remdesivir (GS-5734) Is Efficacious in Cynomolgus Macaques Infected With Marburg Virus. J Infect Dis. 2020 Nov 9;222(11):18941901. doi: 10.1093/infdis/jiaa290

5. Lai CC, Chen $\mathrm{CH}$, Wang $\mathrm{CY}$, Chen $\mathrm{KH}$, Wang YH, Hsueh PR. Clinical efficacy and safety of remdesivir in patients with COVID-19: a systematic review and network meta-analysis of randomized controlled trials. J Antimicrob Chemother. 2021;76(8):1962-8. doi: 10.1093/jac/dkab093

6. Abd-Elsalam S, Ahmed OA, Mansour NO, Abdelaziz DH, Salama M, Fouad MHA, et al. Remdesivir Efficacy in COVID-19 Treatment: A Randomized Controlled Trial. Am J Trop Med Hyg. 2021. doi:10.4269/ajtmh.21-0606 .

7. Barratt-Due A, Olsen IC, Nezvalova-Henriksen K, Kåsine T, Lund-Jo-

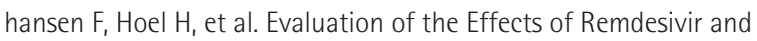
Hydroxychloroquine on Viral Clearance in COVID-19 : A Randomized Trial. Ann Intern Med. 2021. doi:10.7326/m21-0653

8. Spinner CD, Gottlieb RL, Criner GJ, Arribas López JR, Cattelan AM, Soriano Viladomiu A, et al. Effect of Remdesivir vs Standard Care on Clinical Status at 11 Days in Patients With Moderate COVID-19: A Randomized Clinical Trial. Jama. 2020. doi:10.1001/ jama.2020.16349.

9. Wang Y, Zhou F, Zhang D, Zhao J, Du R, Hu Y, et al. Evaluation of the efficacy and safety of intravenous remdesivir in adult patients with severe COVID-19: study protocol for a phase 3 randomized, double-blind, placebo-controlled, multicentre trial. Trials. 2020;21(1):422. doi:10.1186/s13063-020-04352-9 PMC7245636.

10. Sodani P, Mucci L, Girolimetti R, Tedesco S, Monaco F, Campanoz-

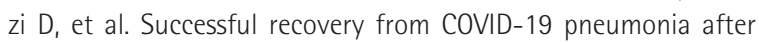
receiving baricitinib, tocilizumab, and remdesivir. A case report: Review of treatments and clinical role of computed tomography analysis. Respir Med Case Rep. 2020;31:101115. doi:10.1016/j. rmcr.2020.101115 PMC7320265

11. Sanders JM, Monogue ML, Jodlowski TZ, Cutrell JB. Pharmacologic Treatments for Coronavirus Disease 2019 (COVID-19): A Review. Jama. 2020. doi: 10.1001/jama.2020.6019

12. Wang $Y$, Zhang D, Du G, Du R, Zhao J, Jin $Y$, et al. Remdesivir in adults with severe COVID-19: a randomised, double-blind, placebo-controlled, multicentre trial. Lancet. 2020;395(10236):1569-78. doi:10.1016/s0140-6736(20)31022-9. 
13. Pan $H_{1}$ Peto $R$, Henao-Restrepo AM, Preziosi MP, Sathiyamoorthy $V_{\text {, }}$ Abdool Karim Q, et al. Repurposed Antiviral Drugs for Covid-19 - Interim WHO Solidarity Trial Results. N Engl J Med. 2021;384(6):497511. doi:10.1056/NEJMoa2023184

14. Ader $F$, Bouscambert-Duchamp $M$, Hites $M$, Peiffer-Smadja $N$, Poissy J, Belhadi D, et al. Remdesivir plus standard of care versus standard of care alone for the treatment of patients admitted to hospital with COVID-19 (DisCoVeRy): a phase 3, randomised, controlled, open-label trial. Lancet Infect Dis. 2021. doi:10.1016/ s1473-3099(21)00485-0

15. Beigel JH, Tomashek KM, Dodd LE, Mehta AK, Zingman BS, Kalil AC, et al. Remdesivir for the Treatment of Covid-19 - Final Report. N Engl J Med. 2020;383(19):1813-26. doi:10.1056/NEJMoa2007764

16. Garcia-Vidal C, Alonso R, Camon AM, Cardozo C, Albiach L, Agüero $D$, et al. Impact of remdesivir according to the pre-admission symptom duration in patients with COVID-19. J Antimicrob Chemother. 2021. doi: $10.1093 / j a c / d k a b 321$

17. Paranjape N, Husain M, Priestley J, Koonjah Y, Watts C, Havlik J. Early Use of Remdesivir in Patients Hospitalized With COVID-19 Improves Clinical Outcomes: A Retrospective Observational Study. Infect Dis Clin Pract (Baltim Md). 2021;29(5):e282-e6. doi:10.1097| ipc.0000000000001023.

18. Hussain Alsayed HA, Saheb Sharif-Askari F, Saheb Sharif-Askari N, Hussain AAS, Hamid Q, Halwani R. Early administration of remdesivir to COVID-19 patients associates with higher recovery rate and lower need for ICU admission: A retrospective cohort study. PLoS One. 2021;16(10):e0258643. doi:10.1371/journal.pone.0258643

19. Sociedad Española de Enfermedades Infecciosas y Microbiología Clínica. Recomendaciones SEIMC para el manejo clínico de pacientes con COVID-19. 2021. Available at: https://covid19seimcorg/ wp-content/uploads/2021/06/SEIMC-Recomendaciones-COVID_14-05-2021pdf..

20. Infectious Disease Society of America. IDSA Guidelines on the Treatment and Management of Patients with COVID-19. 2021. Available at: https://wwwidsocietyorg/practice-guideline/covid-19-guideline-treatment-and-management.

21. Hill JA, Paredes R, Vaca C, BJ W, Perez G, Oguchi G, et al., editors. Remdesivir for the Treatment of High-Risk Non-Hospitalized Individuals With COVID-19: A Randomized, Double-Blind, Placebo-Controlled Triale. Breaker Abstracts: COVID-19 Treatment and Prophylaxis. ID Week 2021; 2021; USA: IDSA.

22. Suzuki M, Imai T, Sakurai A, Komoto S, Ide T, Lim CK, et al. Virological and genomic analysis of SARS-CoV-2 from a favipiravir clinical trial cohort. J Infect Chemother. 2021;27(9):1350-6. doi:10.1016/j. jiac.2021.06.010

23. Dabbous HM, El-Sayed MH, El Assal G, Elghazaly H, Ebeid FFS, Sherief AF, et al. Safety and efficacy of favipiravir versus hydroxychloroquine in management of COVID-19: A randomised controlled trial. Sci Rep. 2021;11(1):7282. doi:10.1038/s41598-021-85227-0.

24. Solaymani-Dodaran $M$, Ghanei $M$, Bagheri M, Qazvini A, Vahedi $E_{1}$ Hassan Saadat $S$, et al. Safety and efficacy of Favipiravir in moderate to severe SARS-CoV-2 pneumonia. Int Immunopharmacol. 2021;95:107522. doi:10.1016/j.intimp.2021.107522
25. Khamis F, Al Naabi H, Al Lawati A, Ambusaidi Z, Al Sharji M, Al Barwani $U$, et al. Randomized controlled open label trial on the use of favipiravir combined with inhaled interferon beta- $1 b$ in hospitalized patients with moderate to severe COVID-19 pneumonia. Int J Infect Dis. 2021;102:538-43. doi: 10.1016/j.ijid.2020.11.008

26. Lou Y, Liu L, Yao H, Hu X, Su J, Xu K, et al. Clinical Outcomes and Plasma Concentrations of Baloxavir Marboxil and Favipiravir in COVID-19 Patients: An Exploratory Randomized, Controlled Trial. Eur J Pharm Sci. 2021;157:105631. doi:10.1016/j.ejps.2020.105631

27. Udwadia ZF, Singh P, Barkate H, Patil S, Rangwala S, Pendse A, et al. Efficacy and safety of favipiravir, an oral RNA-dependent RNA polymerase inhibitor, in mild-to-moderate COVID-19: A randomized, comparative, open-label, multicenter, phase 3 clinical trial. Int J Infect Dis. 2021;103:62-71. doi:10.1016/j.ijid.2020.11.142

28. Joshi S, Parkar J, Ansari A, Vora A, Talwar D, Tiwaskar M, et al. Role of favipiravir in the treatment of COVID-19. Int J Infect Dis. 2021;102:501-8. doi:10.1016/j.ijid.2020.10.069

29. Brown LK, Freemantle N, Breuer J, Dehbi HM, Chowdhury K, Jones $\mathrm{G}$, et al. Early antiviral treatment in outpatients with COVID-19 (FLARE): a structured summary of a study protocol for a randomised controlled trial. Trials. 2021;22(1):193. doi:10.1186/s13063-02105139-2

30. Imran M, Kumar Arora M, Asdaq SMB, Khan SA, Alaqel SI, Alshammari MK, et al. Discovery, Development, and Patent Trends on Molnupiravir: A Prospective Oral Treatment for COVID-19. Molecules. 2021;26(19). doi:10.3390/molecules26195795

31. Fischer W, Eron JJ, Holman W, Cohen MS, Fang L, Szewczyk L, et al. Molnupiravir, an Oral Antiviral Treatment for COVID-19. medRxiv. 2021. doi:10.1101/2021.06.17.21258639

32. Singh $A K$, Singh $A$, Singh $R$, Misra $A$. Molnupiravir in COVID-19: A systematic review of literature. Diabetes Metab Syndr. 2021;15(6):102329. doi:10.1016/j.dsx.2021.102329

33. Willyard C. How antiviral pill molnupiravir shot ahead in the COVID drug hunt. Nature. 2021. doi:10.1038/d41586-021-02783-1.

34. Mahase E. Covid-19: UK becomes first country to authorise antiviral molnupiravir. Bmj. 2021;375:n2697. doi:10.1136/bmj.n2697.

35. Abdelnabi R, Foo CS, Kaptein SJF, Zhang X, Do TND, Langendries $L$, et al. The combined treatment of Molnupiravir and Favipiravir results in a potentiation of antiviral efficacy in a SARS-CoV-2 hamster infection model. EBioMedicine. 2021;72:103595. doi: 10.1016/j.ebiom.2021.103595.

36. Painter WP, Holman W, Bush JA, Almazedi F, Malik H, Eraut N, et al. Human Safety, Tolerability, and Pharmacokinetics of Molnupiravir, a Novel Broad-Spectrum Oral Antiviral Agent with Activity Against SARS-CoV-2. Antimicrob Agents Chemother. 2021;65(5). doi:10.1128/aac.02428-20

37. Holman W, Holman W, Mclntosh S, Painter W, Painter G, Bush J, et al. Accelerated first-in-human clinical trial of EIDD-2801/MK4482 (molnupiravir), a ribonucleoside analog with potent antiviral activity against SARS-CoV-2. Trials. 2021;22(1):561. doi: 10.1186/ s13063-021-05538-5.

38. Kabinger F, Stiller C, Schmitzová J, Dienemann C, Kokic G, Hillen HS, et al. Mechanism of molnupiravir-induced SARS-CoV-2 mutagen- 
esis. Nat Struct Mol Biol. 2021;28(9):740-6. doi:10.1038/s41594021-00651-0.

39. Ahlqvist $\mathrm{GP}, \mathrm{McGeough} \mathrm{CP}$, Senanayake $\mathrm{C}$, Armstrong JD, Yadaw $A$, Roy $S$, et al. Progress Toward a Large-Scale Synthesis of Molnupiravir (MK-4482, EIDD-2801) from Cytidine. ACS Omega. 2021;6(15):10396-402. doi:10.1021/acsomega.1c00772

40. Zhao Y, Fang $C$, Zhang Q, Zhang $R$, Zhao $X$, Duan $Y$, et al. Crystal structure of SARS-CoV-2 main protease in complex with protease inhibitor PF-07321332. Protein Cell. 2021 Oct 22;1-5. doi: 10.1007/ s13238-021-00883-2

41. Owen DR, Allerton CMN, Anderson AS, Aschenbrenner L, Avery M,

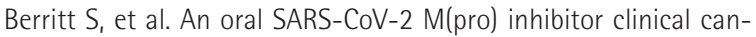
didate for the treatment of COVID-19. Science. 2021:eabl4784. doi:10.1126/science.ab/4784.

42. Pfizer. Pfzer's Novel COVID-19 oral antiviral treatment candidate reduced risk of hospitalization or death by $89 \%$ in interim analysis of phase EPIC-HR Study. Nota de prensa. 2021;Available at: https://www.pfizer.com/news/press-release/press-release-detail/ pfizers-novel-covid-19-oral-antiviral-treatment-candidate.

43. Zuo Z, Wu T, Pan L, Zuo C, Hu Y, Luo X, et al. Modalities and Mechanisms of Treatment for Coronavirus Disease 2019. Front Pharmacol. 2020;11:583914. doi:10.3389/fphar.2020.583914.

44. Katz LM. (A Little) Clarity on Convalescent Plasma for Covid-19. N Engl J Med. 2021;384(7):666-8. doi: 10.1056/NEJMe2035678.

45. Cao H, Ming L, Chen L, Zhu X, Shi Y. The Effectiveness of Convalescent Plasma for the Treatment of Novel Corona Virus Disease 2019: A Systematic Review and Meta-Analysis. Front Med (Lausanne). 2021:8:641429. doi:10.3389/fmed.2021.641429.

46. Aviani JK, Halim D, Soeroto AY, Achmad TH, Djuwantono T. Current views on the potentials of convalescent plasma therapy (CPT) as Coronavirus disease 2019 (COVID-19) treatment: A systematic review and meta-analysis based on recent studies and previous respiratory pandemics. Rev Med Virol. 2021. doi:10.1002/rmv.2225.

47. Li L, Zhang W, Hu Y, Tong X, Zheng S, Yang J, et al. Effect of Convalescent Plasma Therapy on Time to Clinical Improvement in Patients With Severe and Life-threatening COVID-19: A Randomized Clinical Trial. Jama. 2020. doi:10.1001/jama.2020.10044.

48. Simonovich VA, Burgos Pratx LD, Scibona P, Beruto MV, Vallone

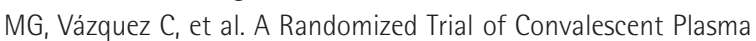
in Covid-19 Severe Pneumonia. N Engl J Med. 2020. doi:10.1056/ NEJMoa2031304.

49. Avendaño-Solá $C$, Ramos-Martínez $A$, Muñez-Rubio $E$, Ruiz-Antorán B, Malo de Molina R, Torres F, et al. A multicenter randomized open-label clinical trial for convalescent plasma in patients hospitalized with COVID-19 pneumonia. J Clin Invest. 2021. doi:10.1172/ jci152740 .

50. Agarwal A, Mukherjee A, Kumar G, Chatterjee P, Bhatnagar T, Malhotra P. Convalescent plasma in the management of moderate covid-19 in adults in India: open label phase II multicentre randomised controlled trial (PLACID Trial). Bmj. 2020;371:m3939. doi:10.1136/ bmj.m3939.

51. Libster R, Pérez Marc G, Wappner D, Coviello S, Bianchi A, Braem V, et al. Early High-Titer Plasma Therapy to Prevent Severe Covid-19 in Older Adults. N Engl J Med. 2021. doi:10.1056/NEJMoa2033700.

52. Gupta A, Gonzalez-Rojas Y, Juarez E, Crespo Casal M, Moya J, Falci DR, et al. Early Treatment for Covid-19 with SARS-CoV-2 Neutralizing Antibody Sotrovimab. N Engl J Med. 2021. doi:10.1056/NEJMoa2107934.

53. (FDA) FaDA. Emergency Use Authorization (EUA) for the emergency use of sotrovimab for the treatment of mild-to-moderate coronavirus disease 2019 (COVID-19). FDA, 2021. (consultado 3 Nov 2021).. Available at: https://wwwfdagov/media/149534/download.

54. Unión Europea de la Salud: La Comisión establece una cartera con los diez tratamientos más prometedores contra la COVID-19. 2021. Available at:https://eceuropaeu/commission/presscorner/detail/es/ ip_21_5366..

55. European Medicines Agency NdP. EMA issues advice on use of sotrovimab (VIR-7831) for treating COVID-19 (accessed 3 Nov 2021). 2021. Available at: https://wwwemaeuropaeu/en/news/ ema-issues-advice-use-sotrovimab-vir-7831-treating-covid-19.

56. An EUA for Bamlanivimab-A Monoclonal Antibody for COVID-19. Jama. 2021;325(9):880-1. doi:10.1001/jama.2020.24415

57. Food and Drug Administration, release P. US Food and Drug Administration. Coronavirus (COVID-19) Update: FDA Revokes Emergency Use Authorization for Monoclonal Antibody Bamlanivimab. FDA; April 16, 2021. (accessed 10 Nov 2021). . Available at: https:// wwwfdagov/media/147629/download.

58. Dougan M, Nirula A, Azizad M, Mocherla B, Gottlieb RL, Chen P, et al. Bamlanivimab plus Etesevimab in Mild or Moderate Covid-19. N Engl J Med. 2021. doi:10.1056/NEJMoa2102685.

59. Chen P, Nirula A, Heller B, Gottlieb RL, Boscia J, Morris J, et al. SARS-CoV-2 Neutralizing Antibody LY-CoV555 in Outpatients with Covid-19. N Engl J Med. 2021;384(3):229-37. doi:10.1056/NEJMoa2029849

60. Euroepan Medicines Agency. Questions and answers on end of rolling review for antibodies bamlanivimab and etesevimab for COVID-19 [Internet]. EMA; November 2, 2021. Bamlanivimab and etesevimab for COVID-19: Withdrawal from the rolling review process. (Consultado el 10 Nov 2021). Available at: https:// wwwemaeuropaeu/en/documents/medicine-qa/questions-answers-end-rolling-review-antibodies-bamlanivimab-etesevimab-covid-19_enpdf.

61. Anonymous. An EUA for casirivimab and imdevimab for COVID-19. Med Lett Drugs Ther. 2020;62(1614):201-2. PMID: 33451174

62. FDA News Release. Coronavirus (COVID-19) update: FDA authorizes monoclonal antibodies for treatment of COVID-19. November 21, 2020. Available at: https://bitly/2/hDxP5 Accessed June 10, 2021. 2020.

63. FDA News Release. Coronavirus (COVID-19) update: May 21, 2021. Available at: https://bitly/3fFoEUB Accessed June 10, 2021. 2021.

64. FDA. Fact sheet for health care providers. Emergency Use Authorization (EUA) of casirivimab and imdevimab.. Available at: https:// bitly/36NmbDm Accessed: June 10, 2021.

65. Copin R, Baum A, Wloga E, Pascal KE, Giordano S, Fulton BO, et al. The monoclonal antibody combination REGEN-COV protects against SARS-CoV-2 mutational escape in preclinical and hu- 
man studies. Cell. 2021;184(15):3949-61.e11. doi: 10.1016/j. cell.2021.06.002

66. FDA News Release. Coronavirus (COVID-19) update: June 4, 2021. . Available at: https://wwwfdagov/news-events/press-announcements/coronavirus-covid-19-update-june-4-2021 Accessed: June 10, 2021. 2021.

67. Mayer C, VanHise K, Caskey R, Naqvi M, Burwick RM. Monoclonal Antibodies Casirivimab and Imdevimab in Pregnancy for Coronavirus Disease 2019 (COVID-19). Obstet Gynecol. 2021. doi:10.1097/ aog.0000000000004603

68. Release FN. Coronavirus (COVID-19) update: May 21. Available at: https://bitly/3fFoEUB, 2021 Accessed: August 5, 2021. 2021.

69. Anonymous. Casirivimab and imdevimab (REGEN-COV) for post-exposure prophylaxis of COVID-19. Med Lett Drugs Ther. 2021;63(1631):130-1. PMID: 34544100

70. O'Brien MP, Forleo-Neto E, Musser BJ, Isa F, Chan KC, Sarkar N, et al. Subcutaneous REGEN-COV Antibody Combination to Prevent Covid-19. N Engl J Med. 2021. doi:10.1056/NEJMoa2109682

71. Dong J, Zost SJ, Greaney AJ, Starr TN, Dingens AS, Chen EC, et al. Genetic and structural basis for SARS-CoV-2 variant neutralization by a two-antibody cocktail. Nat Microbiol. 2021;6(10):1233-44. doi:10.1038/s41564-021-00972-2.

72. Clinical Trials gov. Phase III Randomized, Double-blind, Placebo-controlled, Multi-center Study in Adults to Determine the Safety and Efficacy of AZD7442, a Combination Product of Two Monoclonal Antibodies (AZD8895 and AZD1061), for Post-exposure Prophylaxis of COVID-19. Accessed: https://fdaaatrialstrackernet/ trial/NCT04625972/. 2021.

73. Evering $T$, Giganti $M$, Chew KW, Hughes M, Moser $C$, Wohl DA, et al., editors. LB2 - Safety and Efficacy of Combination SARS-CoV-2 Monoclonal Neutralizing Antibodies (mAb) BRII-196 and BRII-198 in Non-Hospitalized COVID-19 Patients. IDWeek; 2021; USA.

74. Munch MW, Myatra SN, Vijayaraghavan BKT, Saseedharan S, Benfield T, Wahlin RR, et al. Effect of $12 \mathrm{mg}$ vs $6 \mathrm{mg}$ of Dexamethasone on the Number of Days Alive Without Life Support in Adults With COVID-19 and Severe Hypoxemia: The COVID STEROID 2 Randomized Trial. Jama. 2021. doi:10.1001/jama.2021.18295.

75. Angus DC, Derde L, Al-Beidh F, Annane D, Arabi Y, Beane A, et al. Effect of Hydrocortisone on Mortality and Organ Support in $\mathrm{Pa}$ tients With Severe COVID-19: The REMAP-CAP COVID-19 Corticosteroid Domain Randomized Clinical Trial. Jama. 2020. doi:10.1001/ jama.2020.17022.

76. Dequin PF, Heming N, Meziani F, Plantefève G, Voiriot G, Badié J, et al. Effect of Hydrocortisone on 21-Day Mortality or Respiratory Support Among Critically III Patients With COVID-19: A Randomized Clinical Trial. Jama. 2020. doi:10.1001/jama.2020.16761.

77. Jeronimo CMP, Farias MEL, Val FFA, Sampaio VS, Alexandre MAA, Melo GC, et al. Methylprednisolone as Adjunctive Therapy for Patients Hospitalized With Coronavirus Disease 2019 (COVID-19; Metcovid): A Randomized, Double-blind, Phase IIb, Placebo-controlled Trial. Clin Infect Dis. 2021;72(9):e373-e81. doi:10.1093/cid/ ciaa1177 PMC7454320.

78. RECOVERY Collaborative Group HP, Lim WS, Emberson JR, Mafham
M, Bell JL, Linsell L, Staplin N, Brightling C, Ustianowski A, Elmahi E, Prudon B, Green C, Felton T, Chadwick D, Rege K, Fegan C, Chappell LC, Faust SN, Jaki T, Jeffery K, Montgomery A, Rowan K, Juszczak E, Baillie JK, Haynes R, Landray MJ.. Dexamethasone in Hospitalized Patients with Covid-19. . N Engl J Med 2021;384:693-704. 10.1056/ NEJMoa2021436.

79. Ye Z, Wang Y, Colunga-Lozano LE, Prasad M, Tangamornsuksan W, Rochwerg $B$, et al. Efficacy and safety of corticosteroids in COVID-19 based on evidence for COVID-19, other coronavirus infections, influenza, community-acquired pneumonia and acute respiratory distress syndrome: a systematic review and meta-analysis. Cmaj. 2020. doi:10.1503/cmaj.200645.

80. Khaw CR, Richardson C, Bhowmik A, Agbetile J, Rajakulasingam RK. Use of Corticosteroid in Persistent Post-COVID 19 Interstitial Lung Disease. Ann Am Thorac Soc. 2021. doi:10.1513/AnnalSATS.202105-623LE.

81. Rosas IO, Bräu N, Waters $M, G o R C$, Hunter BD, Bhagani S, et al. Tocilizumab in Hospitalized Patients with Severe Covid-19 Pneumonia. N Engl J Med. 2021. doi:10.1056/NEJMoa2028700.

82. Stone JH. Tocilizumab in Patients Hospitalized with Covid-19 Pneumonia. Reply. N Engl J Med. 2021. doi:10.1056/NEJMc2100217.

83. Stone JH, Frigault MJ, Serling-Boyd NJ, Fernandes AD, Harvey L, Foulkes AS, et al. Efficacy of Tocilizumab in Patients Hospitalized with Covid-19. N Engl J Med. 2020. doi: 10.1056/NEJMoa2028836.

84. Stone JH, Horick NK, Healy BC. Tocilizumab in Covid-19. Reply. N Engl J Med. 2020;384(1). doi: 10.1056/NEJMc2032911.

85. Stone $\mathrm{JH}_{1}$, Horick NK, Healy BC. Tocilizumab in Covid-19. Reply. N Engl J Med. 2021;384(1):87. doi:10.1056/NEJMc2032911.

86. Salama C, Han J, Yau L, Reiss WG, Kramer B, Neidhart JD, et al. Tocilizumab in Patients Hospitalized with Covid-19 Pneumonia. N Engl J Med. 2021;384(1):20-30. doi:10.1056/NEJMoa2030340

87. Salama C, Mohan SV. Tocilizumab in Patients Hospitalized with Covid-19 Pneumonia. Reply. N Engl J Med. 2021. doi:10.1056/NEJMc2100217.

88. Gordon AC, Mouncey PR, Al-Beidh F, Rowan KM, Nichol AD, Arabi YM, et al. Interleukin-6 Receptor Antagonists in Critically III Patients with Covid-19. N Engl J Med. 2021. doi:10.1056/NEJMoa2100433.

89. Azithromycin in patients admitted to hospital with COVID-19 (RECOVERY): a randomised, controlled, open-label, platform trial. Lancet. 2021;397(10274):605-12. doi: 10.1016/s0140-6736(21)001495

90. Xu X, Han M, Li T, Sun W, Wang D, Fu B, et al. Effective treatment of severe COVID-19 patients with tocilizumab. Proc Natl Acad Sci U S A. 2020. doi:10.1073/pnas.2005615117.

91. Martínez-Sanz J, Muriel A, Ron R, Herrera S, Pérez-Molina JA, Moreno $S$, et al. Effects of tocilizumab on mortality in hospitalized patients with COVID-19: A multicenter cohort study. Clin Microbiol Infect. 2020. doi:10.1016/j.cmi.2020.09.021.

92. Kalil AC, Patterson TF, Mehta AK, Tomashek KM, Wolfe CR, Ghaz-

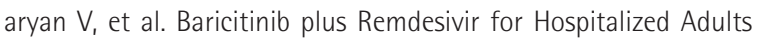
with Covid-19. N Engl J Med. 2021;384(9):795-807. doi:10.1056/ NEJMoa2031994 
93. Guimarães PO, Quirk D, Furtado RH, Maia LN, Saraiva JF, Antunes MO, et al. Tofacitinib in Patients Hospitalized with Covid-19 Pneumonia. N Engl J Med. 2021. doi:10.1056/NEJMoa2101643

94. Marconi VC, Ramanan AV, de Bono S, Kartman CE, Krishnan V, Liao $\mathrm{R}$, et al. Efficacy and safety of baricitinib for the treatment of hospitalised adults with COVID-19 (COV-BARRIER): a randomised, double-blind, parallel-group, placebo-controlled phase 3 trial. Lancet Respir Med. 2021. doi: 10.1016/s2213-2600(21)00331-3.

95. Stebbing J, Phelan A, Griffin I, Tucker C, Oechsle O, Smith D, et al. COVID-19: combining antiviral and anti-inflammatory treatments. Lancet Infect Dis. 2020;20(4):400-2. doi:10.1016/s14733099(20)30132-8.

96. Cavalli G, De Luca G, Campochiaro C, Della-Torre E, Ripa M, Canetti $D$, et al. Interleukin-1 blockade with high-dose anakinra in patients with COVID-19, acute respiratory distress syndrome, and hyperinflammation: a retrospective cohort study. Lancet Rheumatol. 2020;2(6):e325-e31. doi: 10.1016/s2665-9913(20)30127-2

97. Cauchois R, Koubi M, Delarbre D, Manet C, Carvelli J, Blasco VB, et al. Early IL-1 receptor blockade in severe inflammatory respiratory failure complicating COVID-19. Proc Natl Acad Sci U S A. 2020;117(32):18951-3. doi:10.1073/pnas.2009017117

98. Kyriazopoulou E, Huet T, Cavalli G, Gori A, Kyprianou M, Pickkers $P$, et al. Effect of anakinra on mortality in patients with COVID-19: a systematic review and patient-level meta-analysis. Lancet Rheumatol. 2021;3(10):e690-e7. doi:10.1016/s26659913(21)00216-2.

99. Kyriazopoulou E, Poulakou G, Milionis H, Metallidis S, Adamis G, Tsiakos K, et al. Early treatment of COVID-19 with anakinra guided by soluble urokinase plasminogen receptor plasma levels: a double-blind, randomized controlled phase 3 trial. Nat Med. 2021;27(10):1752-60. doi:10.1038/s41591-021-01499-z .

100. Coronavirus disease 19 (COVID19). Straight to the point of care. Emerging treatments. BMJ Best Practice Accessed: https://bestpracticebmjcom/topics/en-gb/3000201/emergingtxs. 2021.

101. World Health Organization. Therapeutics and COVID-19: living guideline. Accessed: https://wwwwhoint/publications/ilitem/ WH0-2019-nCoV-therapeutics-20213. 2021.

102. Temple $C_{1}$ Hoang $R$, Hendrickson RG. Toxic Effects from Ivermectin Use Associated with Prevention and Treatment of Covid-19. N Engl J Med. 2021. doi:10.1056/NEJMc2114907.

103. Dyer 0. Covid-19: Hospital may cease giving patient ivermectin, US court rules, as prescriptions soar. Bmj. 2021;374:n2228. doi:10.1136/bmj.n2228.

104. Vallejos J, Zoni R, Bangher M, Villamandos S, Bobadilla A, Plano $F_{\text {, et }}$ al. Ivermectin to prevent hospitalizations in patients with COVID-19 (IVERCOR-COVID19) a randomized, double-blind, placebo-controlled trial. BMC Infect Dis. 2021;21(1):635. doi:10.1186/ s12879-021-06348-5.

105. RECOVERY Collaborative Group. Colchicine in patients admitted to hospital with COVID-19 (RECOVERY): a randomised, controlled, open-label, platform trial. Lancet Respir Med. 2021 Dec;9(12):14191426. doi: 10.1016/S2213-2600(21)00435-5.

106. Centre for Evidence-Based Medicine, Ferner RE, Sofat R, JK. A. Drug vignettes: colchicine. 2021. Accessed: https://wwwcebmnet/covid-19/colchicine/..

107. National Institutes of Health. Coronavirus disease 2019 (COVID-19) treatment guidelines. Accessed: https://wwwcovid19treatmentguidelinesnihgov/.

108. Stroehlein JK, Wallqvist J, lannizzi C, Cochrane Database Syst. Rev. Vitamin D supplementation for the treatment of COVID-19: a living systematic review. Cochrane Database Syst Rev 2021 May 24;(5):CD015043. doi: 10.1002/14651858.CD015043.

109. Entrenas Castillo M, Entrenas Costa LM, Vaquero Barrios JM, Alcalá Díaz JF, López Miranda J, Bouillon R, et al. "Effect of calcifediol treatment and best available therapy versus best available therapy on intensive care unit admission and mortality among patients hospitalized for COVID-19: A pilot randomized clinical study". J Steroid Biochem Mol Biol. 2020;203:105751. doi:10.1016/j.jsbmb.2020.105751.

110. Ibrahim S, Lowe JR, Bramante CT, Shah S, Klatt NR, Sherwood N, et al. Metformin and Covid-19: Focused Review of Mechanisms and Current Literature Suggesting Benefit. Front Endocrinol (Lausanne). 2021;12:587801. doi:10.3389/fendo.2021.587801.

111. Kow CS, Hasan SS. Mortality risk with preadmission metformin use in patients with COVID-19 and diabetes: A meta-analysis. J Med Virol. 2021;93(2):695-7. doi:10.1002/jmv.26498.

112. Reis G, Dos Santos Moreira-Silva EA, Silva DCM, Thabane L, Milagres AC, Ferreira TS, et al. Effect of early treatment with fluvoxamine on risk of emergency care and hospitalisation among patients with COVID-19: the TOGETHER randomised, platform clinical trial. Lancet Glob Health. 2021. doi:10.1016/s2214-109x(21)00448-4.

113. World health Organization. "Solidarity" clinical trial for COVID-19 treatments: Update on hydroxychloroquine [consultado 9 de julio de 2020]. Accessed: https://wwwwhoint/emergencies/diseases/ novel-coronavirus-2019/global-research-on-novel-coronavirus-2019-ncov/solidarity-clinicaltrial-

114. Horby P, Mafham M, Linsell L, Bell JL, Staplin N, Emberson JR, et al. Effect of Hydroxychloroquine in Hospitalized Patients with Covid-19. N Engl J Med. 2020. doi:10.1056/NEJMoa2022926.

115. Zarogoulidis P, Papanas N, Kioumis I, Chatzaki E, Maltezos E, Zarogoulidis K. Macrolides: from in vitro anti-inflammatory and immunomodulatory properties to clinical practice in respiratory diseases. Eur J Clin Pharmacol. 2012;68(5):479-503. doi:10.1007/s00228011-1161-x.

116. Min JY, Jang YJ. Macrolide therapy in respiratory viral infections. Mediators Inflamm. 2012;2012:649570. doi:10.1155/2012/649570.

117. Lee N, Wong CK, Chan MCW, Yeung ESL, Tam WWS, Tsang OTY, et al. Anti-inflammatory effects of adjunctive macrolide treatment in adults hospitalized with influenza: A randomized controlled trial. Antiviral Res. 2017;144:48-56. doi:10.1016/j.antiviral.2017.05.008.

118. Kawamura K, Ichikado K, Takaki M, Eguchi Y, Anan K, Suga M. Adjunctive therapy with azithromycin for moderate and severe acute respiratory distress syndrome: a retrospective, propensity score-matching analysis of prospectively collected data at a single center. Int J Antimicrob Agents. 2018;51(6):918-24. doi:10.1016/j. ijantimicag.2018.02.009. 
119. Mangkuliguna G, Glenardi, Natalia, Pramono LA. Efficacy and Safety of Azithromycin for the Treatment of COVID-19: A Systematic Review and Meta-analysis. Tuberc Respir Dis (Seoul). 2021;84(4):299316. doi:10.4046/trd.2021.0075

120. Alhumaid S, Mutair AA, Alawi ZA, Alhmeed N, Zaidi ARZ, Tobaiqy M. Efficacy and Safety of Lopinavir/Ritonavir for Treatment of COVID-19: A Systematic Review and Meta-Analysis. Trop Med Infect Dis. 2020;5(4). doi:10.3390/tropicalmed5040180 .

121. Chan JF, Yao Y, Yeung ML, Deng W, Bao L, Jia L, et al. Treatment With Lopinavir/Ritonavir or Interferon-beta1b Improves Outcome of MERS-CoV Infection in a Nonhuman Primate Model of Common Marmoset. J Infect Dis. 2015;212(12):1904-13. doi:10.1093/infdis/ jiv392.

122. World Health Organization. Women of reproductive age (15-46 years) population. . Available at: https//wwwwhoint/data/maternal-newborn-child-adolescent/indicator-explorer-new/mca/women-of--reproductive-age (15-49-years)-population-(thousands) Accessed: 20 April 2020. 2020.

123. Ko JY, DeSisto CL, Simeone RM, Ellington $S$, Galang RR, Oduyebo T, et al. Adverse Pregnancy Outcomes, Maternal Complications, and Severe IIIness Among US Delivery Hospitalizations With and Without a Coronavirus Disease 2019 (COVID-19) Diagnosis. Clin Infect Dis. 2021;73(Suppl 1):S24-s31. doi:10.1093/cid/ciab344

124. Woodworth KR, Olsen EO, Neelam V, Lewis EL, Galang RR, Oduye-

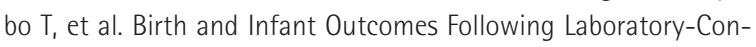
firmed SARS-CoV-2 Infection in Pregnancy - SET-NET, 16 Jurisdictions, March 29-October 14, 2020. MMWR Morb Mortal Wkly Rep. 2020;69(44):1635-40. doi:10.15585/mmwr.mm6944e2

125. Sociedad Española de Obstetricia y Ginecología. Actualización documento técnico. Manejo de la mujer embarazada y el recién nacido con COVID_19. Version 17 junio 2020, pag 1-32. Accessed: https:// segoes/infoCovid-19.

126. Pastick KA, Nicol MR, Smyth E, Zash R, Boulware DR, Rajasingham $R$, et al. A Systematic Review of Treatment and Outcomes of Pregnant Women With COVID-19-A Call for Clinical Trials. Open Forum Infect Dis. 2020;7(9):ofaa350. doi:10.1093/ofid/ofaa350

127. Martínez-Sánchez N, De la Calle Fernández-Miranda M, Bartha JL. Safety profile of treatments administered in COVID 19 infection in pregnant women. Clin Invest Ginecol Obstet. 2021;48(3):100663. doi:10.1016/j.gine.2021.01.004

128. Pattanashetti L, Patil S, Nyamgouda $S$, Bhagiratha $M$, Gadad P. COVID-19 and pregnant women. An overview on diagnosis, treatment approach with limitation, and clinical management. Monaldi Arch Chest Dis. 2021;91(3). doi:10.4081/monaldi.2021.1785.

129. Centers for Disease Control and Prevention. Covid-19: information for pediatric healthcare providers.2020. . Available at: https://wwwcdcgov/coronavirus/2019-ncov/hcp/pediatric-hcphtml Accessed: March26,2021. 2020.

130. Dong $Y$, Mo $X, H u Y$, Qi $X$, Jiang F, Jiang $Z$, et al. Epidemiology of COVID-19 Among Children in China. Pediatrics. 2020. doi: 10.1542/ peds.2020-0702

131. Livingston E, Bucher K. Coronavirus Disease 2019 (COVID-19) in Italy. Jama. 2020. doi:10.1001/jama.2020.4344.
132. Swann OV, Holden KA, Turtle L, Pollock L, Fairfield CJ, Drake TM, et al. Clinical characteristics of children and young people admitted to hospital with covid-19 in United Kingdom: prospective multicentre observational cohort study. Bmj. 2020;370:m3249. doi: 10.1136/ bmj.m3249.

133. Shekerdemian LS, Mahmood NR, Wolfe KK, Riggs BJ, Ross CE, McKiernan CA, et al. Characteristics and Outcomes of Children With Coronavirus Disease 2019 (COVID-19) Infection Admitted to US and Canadian Pediatric Intensive Care Units. JAMA Pediatr. 2020;174(9):868-73. doi:10.1001/jamapediatrics.2020.1948

134. Götzinger $F$, Santiago-García $B$, Noguera-Julián $A$, Lanaspa $M$, Lancella $\mathrm{L}$, Calò Carducci Fl, et al. COVID-19 in children and adolescents in Europe: a multinational, multicentre cohort study. Lancet Child Adolesc Health. 2020;4(9):653-61. doi:10.1016/s23524642(20)30177-2

135. Tagarro A, Epalza C, Santos M, Sanz-Santaeufemia FJ, Otheo E, Moraleda $C_{1}$ et al. Screening and Severity of Coronavirus Disease 2019 (COVID-19) in Children in Madrid, Spain. JAMA Pediatr. 2020. doi:10.1001/jamapediatrics.2020.1346.

136. de Rojas T, Pérez-Martínez A, Cela E, Baragaño M, Galán V, Mata $C$, et al. COVID-19 infection in children and adolescents with cancer in Madrid. Pediatr Blood Cancer. 2020;67(7):e28397. doi:10.1002/ pbc.28397

137. Centers for disease Control and Prevention. Information for health providers about multisystem inflammatory syndrome in children (MIS-C). 2021 . Available at: https://wwwcdcgov/mi-c/hcp/ Accessed: March 26, 2021.

138. Carlin RF, Fischer AM, Pitkowsky Z, Abel D, Sewell TB, Landau EG, et al. Discriminating Multisystem Inflammatory Syndrome in Children Requiring Treatment from Common Febrile Conditions in Outpatient Settings. J Pediatr. 2021;229:26-32.e2. doi:10.1016/j. jpeds.2020.10.013

139. National Institutes of Health, Covid-19 Treatment Guidelines Panel. Coronavirus Disease 2019 (COVID 19). Treatment Guidelines. Accessed:https://wwcovid19 treatmentguidelines nihgov/ 11/12/2021. 2021.

140. Food and Drug Administration. Fact sheet for healthcare providers : emergency use authorization (EUA) of veklury (remdesivir) for hospitalized pediatric patients weighing $3.5 \mathrm{~kg}$ to less than $40 \mathrm{~kg}$ or hospitalized pediatric patients less than 12 years of age weighing at least 3.5kg. 2020- Accessed: https://wwwfdagov/media/1375667. 2020.

141. Wolf J, Abzug MJ, Wattier RL, Sue PK, Vora SB, Zachariah P, et al. Initial Guidance on Use of Monoclonal Antibody Therapy for Treatment of Coronavirus Disease 2019 in Children and Adolescents. J Pediatric Infect Dis Soc. 2021;10(5):629-34. doi:10.1093/jpids/ piaa 175

142. Ouldali N, Toubiana J, Antona D, Javouhey E, Madhi F, Lorrot M, et al. Association of Intravenous Immunoglobulins Plus Methylprednisolone vs Immunoglobulins Alone With Course of Fever in Multisystem Inflammatory Syndrome in Children. Jama. 2021. doi: 10.1001/ jama.2021.0694.

143. Ficha técnica. Veklury $100 \mathrm{mg}$ concentrado para solución para per- 
fusión. Consultado el 1 de Noviembre de 2021. Accessed: https:// cimaaempses/cima/dochtml/ft/1201459001/FT_1201459001html). 2020.

144. Sarzani R, Spannella F, Giulietti F, Di Pentima C, Giordano P, Giacometti A. Possible harm from glucocorticoid drugs misuse in the early phase of SARS-CoV-2 infection: a narrative review of the evidence. Intern Emerg Med. 2021:1-10. doi: 10.1007/s11739-02102860-3

145. European Medicines Agency. EMA issues advice on use of sotrovimab (VIR-7831) for treating COVID-19. Accessed: https://wwwemaeuropaeu/en/news/ema-issues-advice-use-sotrovimab-vir7831-treating-covid-19; 2021. November 1, 2021

146. European Medicines Agency. EMA issues advice on use of REGNCOV2 antibody combination (casirivimab / imdevimab).2021. Accessed: https://wwwemaeuropaeu/en/news/ema-issues-advice-use-regn-cov2-antibody-combination-casirivimab-imdevimab). 